\title{
Relative Influence of Environmental Factors on Biodiversity and Behavioural Traits of a Rare Mesopelagic Fish, Trachipterus trachypterus (Gmelin, 1789), in a Continental Shelf Front of the Mediterranean Sea
}

\author{
Armando Macali ${ }^{1, *}$, Alexander Semenov ${ }^{2}\left(\mathbb{D}\right.$, Francesco Paladini de Mendoza ${ }^{3}$, Alessia Dinoi ${ }^{4}(\mathbb{D}$, \\ Elisa Bergami ${ }^{5}$ and Francesco Tiralongo ${ }^{3,6}$ (D) \\ 1 Department of Ecological and Biological Sciences, Ichthyogenic Experimental Marine Center (CISMAR), \\ University of Tuscia, 01016 Tarquinia, Italy \\ 2 N. A. Pertsov White Sea Biological Research Station, Department of Biology, Lomonosov Moscow State \\ University, 119991 Moscow, Russia; semenov@wsbs-msu.ru \\ 3 Ente Fauna Marina Mediterranea, 96012 Avola, Italy; framendoza1985@gmail.com (F.P.d.M.); \\ francesco.tiralongo@unict.it (F.T.) \\ 4 Center for Ecological Genomics and Wildlife Conservation, Department of Zoology, University of \\ Johannesburg, Auckland Park 2006, South Africa; alexiadinoi@gmail.com \\ 5 Department of Physical, Earth and Environmental Sciences, University of Siena, Via Mattioli 4, 53100 Siena, \\ Italy; elisa.bergami@unisi.it \\ 6 Department of Biological, Geological and Environmental Sciences, University of Catania, 95129 Catania, Italy \\ * Correspondence: a.macali@unitus.it
}

Received: 7 July 2020; Accepted: 30 July 2020; Published: 2 August 2020

\begin{abstract}
Coastal environments can be influenced by water body masses with particular physical, chemical, and biological properties that create favourable conditions for the development of unique planktonic communities. In this study, we investigated a continental shelf front at Ponza Island (Tyrrhenian Sea) and discussed its diversity and complexity in relation to major environmental parameters. Moon phase and current direction were found to play a significant role in shaping species abundance and behaviour. During in situ observations, we also provided the first data on the behaviour of juveniles of a rare mesopelagic species, Trachipterus trachypterus, suggesting the occurrence of Batesian mimicry.
\end{abstract}

Keywords: Trachipteridae; Ponza Island; upwelling; plankton diversity; Batesian mimicry

\section{Introduction}

Open water environments are highly dynamic ecosystems [1], with ecological processes spreading over a wide range of spatial and temporal scales [2]. At a meso- and sub-mesoscale $(\sim 1-100 \mathrm{~km})$, these processes emerge as dominant structuring regimes for populations of marine organisms in the short time span (days to months) [3,4], encompassing key biological dynamics, such as bloom lifetime or behavioural switches of marine predators [5]. These ecological processes are particularly relevant for drifting organisms (plankton) that are advected and dispersed by the ocean currents [6]. Within this complex scenario, sampling probabilities for uncommon and little-known species can be higher than those reported in all other marine environments, in which these species are typically rare and occur at low abundances. This may result in uncertainty about the real species abundances and their ecological traits. As a result, modern biodiversity surveillance programs often investigate the occurrence of species mostly present at moderate-to-high abundance level $[7,8]$. 
The complex interactions between coastal morphology and sea surface circulation of the Mediterranean Sea promote a high degree of ecosystem patchiness [9]. The environmental characteristics (e.g., salinity and temperature), as well as the dynamics of enrichment processes in the water column [5], lead to differences in distribution and abundance of pelagic species [10-12]. While marine macro-ecology has benefited from the analysis of spatially extensive data sites, inferences about ecological processes are better evaluated by dynamic data collection over temporal scales on a smaller geographic range [13]. Animal behaviour also affect assemblage composition, as for species displaying avoidance behaviour (e.g., due to increased predation risk) or with small home ranges, which are less likely to be observed than schooling or highly mobile species [14].

Within the Mediterranean fish biodiversity, little is still known on mesopelagic communities. Among deep water species, representatives of the family Trachipteridae Swainson, 1839 (order Lampriformes) are rare encounters. They are represented by 10 species distributed in 3 genera [15]: Desmodema (Walters and Fitch, 1960), Trachipterus (Goüan, 1770), and Zu (Walters and Fitch, 1960) [16]. Of these, only Trachipterus arcticus (Brünnich, 1788), Trachipterus trachypterus (Gmelin, 1789) and $\mathrm{Zu}$ cristatus (Bonelli, 1819) have been reported in the Mediterranean Sea. The former is a North Atlantic species, with a single record in the Mediterranean Sea from Spain [17]. The other two species, T. trachypterus and Z. cristatus, reported from tropical and temperate waters of all oceans, have been found in several Mediterranean areas [18-27]. In the Mediterranean Sea, fish of this family are accidentally caught with professional fishing gears, but always in low numbers [20,25,28]. Given the complexity of mesopelagic environments, an understanding of the triggers for the distribution of rare mesopelagic species requires a more comprehensive knowledge of the temporal pattern of environmental variation in a variety of timescales. For this reason, long-term environmental monitoring at aggregation sites is of critical importance.

With the present study, we examined the extent to which key features of the hydrodynamic environment predict the presence of T. trachypterus in a Mediterranean continental shelf front over a 21-days timescale. Using multivariate hierarchical analysis, we examined the temporal changes in species occurrence at an aggregation site. Field observations over time have allowed us to discuss on the drivers affecting the occurrence at particular times and on some relevant ecological and behavioural traits of these species.

\section{Materials and Methods}

\subsection{Study Area and Sampling Design}

The study was performed in the framework of the AQUATILIS EXPEDITION at Ponza Island (Tyrrhenian Sea, Italy) from the 8th to the 28th of April 2018. Due to its bathymetric profile, the area is exposed to prominent surface and upwelling filaments, resulting in a complex hydrodynamism that favours the accumulation of planktonic species in patched areas, according to the prevalent weather forcing [29]. Diving sites were close to "Secca delle Formiche" (40.884947 $\left.\mathrm{N}, 12.978043^{\circ} \mathrm{E}\right)$, a group of emerged rocks, located 0.8 nautical miles $(\mathrm{nm})$ SE from the port of Ponza. The bank rapidly sinks from a depth of $5 \mathrm{~m}$ to over $500 \mathrm{~m}$ (Figure 1), representing a suitable place to study the upwelling of deep mesopelagic species.

Previous surveys conducted in April 2016 and 2017 highlighted a remarkable difference in plankton abundance and biodiversity in the study area according to time; in particular, observation during night dives showed a more complex plankton biodiversity, if compared with day dives (authors' personal note). As a consequence, in the present study, scuba night dives have been planned to start one hour after sunset. Two different groups of three divers each equipped with Nikon D850 with $50 \mathrm{~mm}$ f2 Zeiss Milvus macro lens for photography, Panasonic Lumix GH5 with Panasonic Lumix G $8 \mathrm{~mm}$ f3.5 fish eye and Panasonic Lumix $15 \mathrm{~mm}$ f1.7 lenses for video and tools (fine mesh hand nets, $250 \mathrm{~mL}$ plastic cans) for sampling collection, performed alternate dives. In order to increase the image quality, all the cameras were equipped with a buoyancy stabilization system. Sampling depth varied 
between 0.5 and $10 \mathrm{~m}$, freely drifting within the surface current. To ensure taxon identity, 4 specimens of T. trachypterus were collected and analyzed for morphological traits. Behaviour was recorded by filming all the specimens detected. Observations followed the same schedule, starting one hour after sunset, freely drifting in the first $10 \mathrm{~m}$ of the water column. Surveys were conducted daily between 21:00 and 24:00 $\mathrm{h}$.

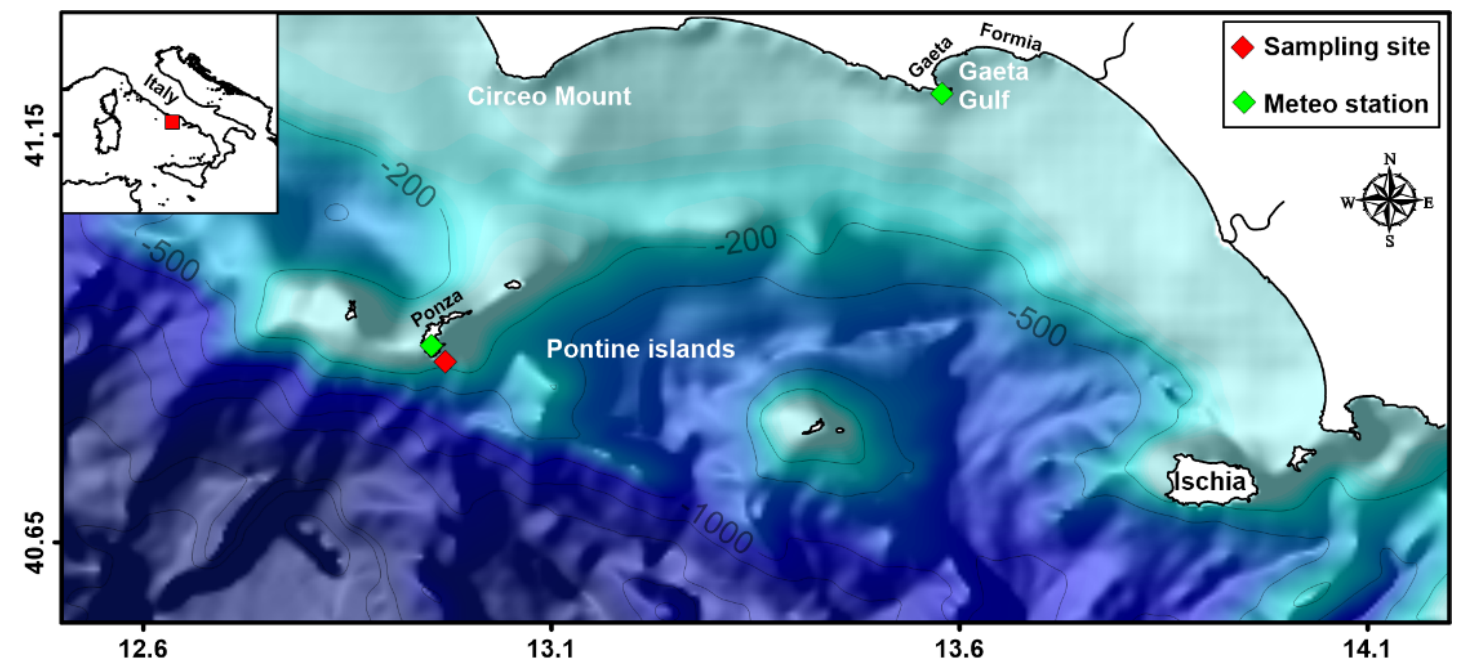

Figure 1. Regional view of the coastal site with the localization of the study area (Ponza Island, within the Pontine Island archipelago) and weather station used for the physical process analysis.

\subsection{Environmental Data Collection}

Main abiotic environmental conditions were inferred from numerical models and in situ measurements (current direction). To this aim, wind records from available meteorological station and numerical results of Surface Sea Temperature (SST) and Salinity (SS) were collected considering both surveying period and long-time series. The wind records were downloaded from the Gaeta Port Authority and the Mareographic network websites (www.mareografico.it; www.portidiroma.it). Ponza's records extend only for a 4-year period (2011-2015), while more than 10-year records are available from Gaeta (2007-2018) (Supplementary Materials, Figure S1). Despite the distance between stations, wind roses can be considered comparable [29,30]. During surveys, we used Gaeta Meteo Station period to analyse wind conditions. The SST and SS datasets were downloaded from the "Copernicus" data portal (http://marine.copernicus.eu, accessed on the 21st of November 2018). SST and SS from 1987 to present were analysed, producing long-term temporal mean distribution of variables during April months and mean conditions during the surveyed period.

Moonlight is known to affect zooplankton and micro-nekton dynamics, as well as their predators in tropical, subtropical, and Arctic waters [31-36]. Moonlight also drives vertical migrations to bathypelagic depths ( $\sim 1000 \mathrm{~m})$ involving a cascade response, with deeper-living organisms responding to movements of shallower-living, surface-synchronized populations [37]. According to this evidence, the main macro-zooplanktonic species composition was recorded and correlated to moon phases and moonlight intensity.

\subsection{Data Analysis}

Non-parametric multivariate analyses were performed to assess the relation between the species observed and the environmental parameters over the survey time period. To analyze the environmental conditions (SST, moon phase, wind direction, and current direction), the parameters were normalized and standardized to carry out a Principal Component Analysis (PCA) with Statistical Package for Social Science (SPSS, Version 26.0, IBM Corp $(2019)$. Once the significant environmental patterns were established, standardized data of the observed species were used to investigate the variability of these patterns. To assess variations in the species diversity, data of the thirty-five taxa were analyzed 
using distance-based permutational multivariate analysis of variance (PERMANOVA) $[38,39]$ with the method of permutation of the residuals under a reduced model, according to a 2-factor nested design: moon phase and current direction. The homogeneity of multivariate dispersions was tested with the PERMDISP routine, mainly to estimate dispersion at the moon phase level. Non-parametric multidimensional scaling ordination (nMDS) was used to examine the behaviour of the species grouped according to the current direction pattern. The Similarity Percentage analysis procedure (SIMPER) was used to identify the main species that characterized each current direction pattern. These analyses were performed on Primer v.7 with PERMANOVA+ software [39,40]. A PCA with supplementary variables was performed with CANOCO 5 [41] in order to investigate the species response to each variable. Finally, the hierarchical cluster analysis was applied to estimate the number of clusters using Primer v.7 [40].

\section{Results}

\subsection{Oceanographic Landscape}

Available time-lapse records of Ponza Island and Gaeta showed three main directions (North-East, South-East and West-Northwest) of wind. Between the 12th and the 18th of April 2018, a moderate north-west wind dominated, while in the other days, weak northern flows (8th-11th of April) and eastern flows (19th-28th of April) were recorded (Supplementary Materials, Figure S2B). The SST mean distribution of April showed a quite uniform temperature at a regional scale, with variations of less than $1{ }^{\circ} \mathrm{C}\left(16.8-17.6^{\circ} \mathrm{C}\right)$. Between the 9th and the 18th of April 2018, the SST was generally cooler than the mean long-term map, with a weak NW-SE increasing gradient. In correspondence of the study area, the SST reached $15.3-15.5^{\circ} \mathrm{C}$. After the 18 th of April, a sensitive increase (more than $2{ }^{\circ} \mathrm{C}$ ) in SST occurred at a regional scale (Supplementary Materials, Figure S2A). SS mean distribution map (Supplementary Materials, Figure S2C) shows the effect of continental waters (Volturno River) which reduced SS in the nearshore. In the study site, the SS reached 38 psu on the 9th-11th of April 2018, slowly decreasing until the end of the survey (Supplementary Materials, Figure S2C).

\subsection{Assemblages}

A total of 35 families of meso- and macroplankton taxa has been recorded over the whole studied period, together with the associated environmental factors (Supplementary Materials, Table S1). The species list included pelagic predators (Forskaliidae, Ommastrephidae, Pelagidae, and Phronimidae) as well as planktivorous species (Alciopydae, Fritillariidae, Leucotheidae, Mysidae, and Salpidae) representing exploiting food characteristics of the current fronts. Details of the trophic and reproductive behaviour of these species are reported in the Supplementary Materials (Plate I-III).

\subsection{Role of Environmental Factors}

The PCA model computed with SPSS explained more than $90 \%$ of the variability for the considered environmental variables (Figure 2). Based on these results and the PERMANOVA, two environmental patterns were retained as main factors: the moon phase $(p$-value $=0.0011)$ and the current direction $(p$-value $=0.0015)$. The SST did not play a significant role in species composition and diversity, while showing high variability (range $14.5-19^{\circ} \mathrm{C}$ ) in the surveyed period.

Moonlight seems to rule the occurrence and abundance of plankton in the surface layer of the water column, with a clear increase in the occurrence of 12 taxa, consequently to the extremes of the moon phase (see Supplementary Materials, Figure S3). With the exception of Cestidae, all the other taxa included in this group showed a negative correlation to moonlight, as for Nereidae and Sepiolidae, which was also correlated to the record of mating behaviour (see Supplementary Materials, Plate I-II). Juvenile and larval stages of benthic and benthopelagic species, as Pleuronectiformes, Phycidae, Anguilliformes, and Scyllaridae, also negatively responded to moonlight. 


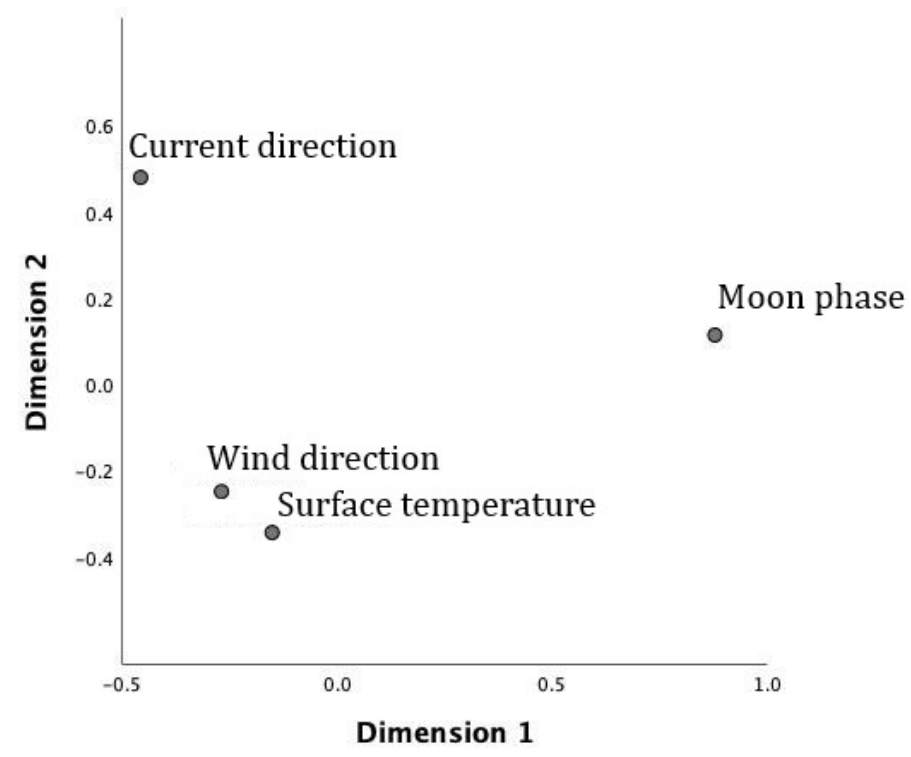

Figure 2. Principal component analysis (PCA) of the environmental factors (performed with SPSS).

According to the observed pattern, the most abundant taxon during the main Eastern flow direction was represented by Forskaliidae, while in the least North-Western flow the most abundant taxon was represented by Alciopidae.

The PCA model performed with CANOCO 5 shows correlations among moon phase, current directions, and taxa. It is possible to observe how most taxa took the opposite direction as the moon phase progressed and how the main current blows eastward (Figure 3a). Arrows indicate the direction of the taxa at increasing values of the environmental variables, with longer vectors representing a greater range of variation in the observed values (Figure 3b). A stronger correlation is associated to more acute angles between vectors and the axes. The $x$ axis explains $57.6 \%$ of the variation among parameters at each taxon, whereas the y axis explains $47.1 \%$ (Figure $3 a, b$ ).
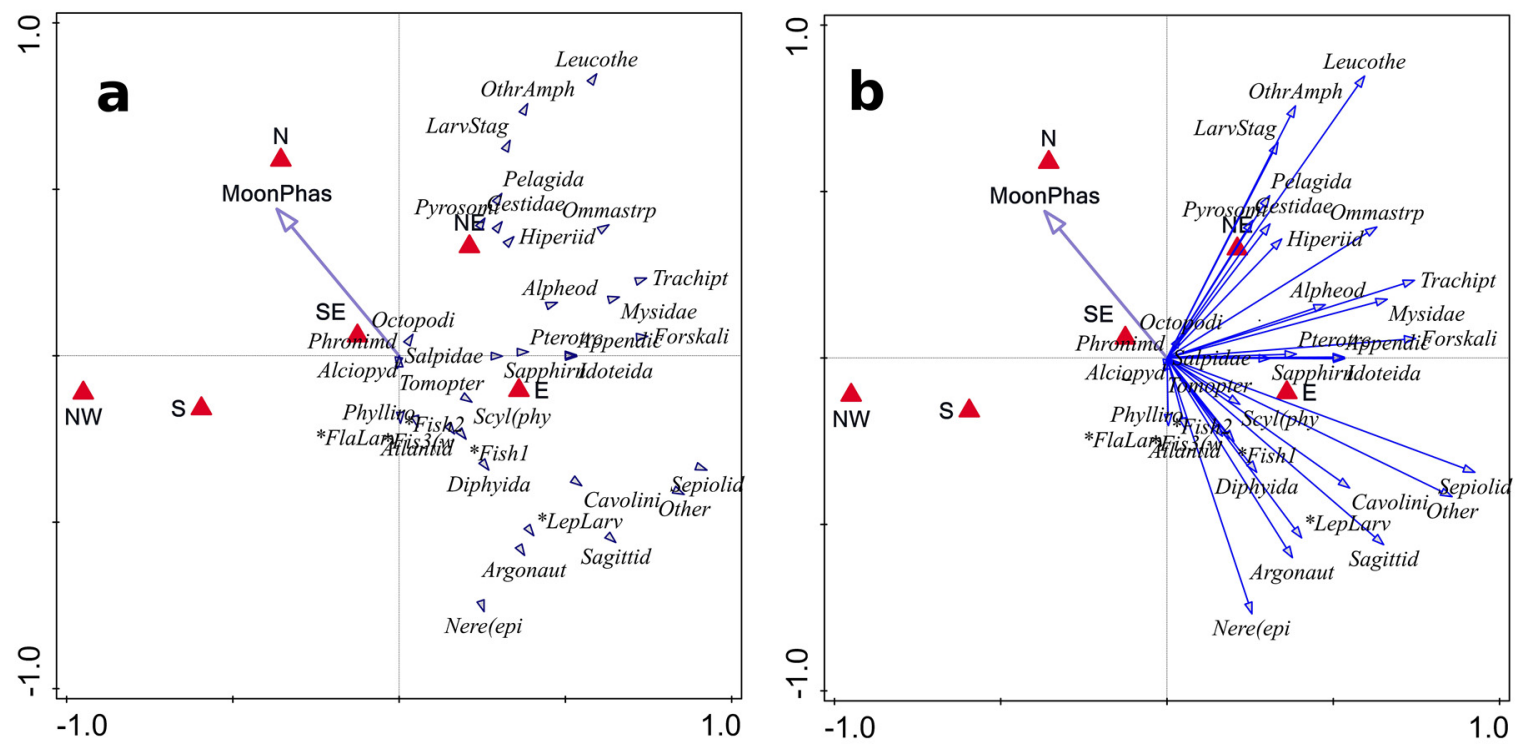

Figure 3. PCA (a) of the encountered taxa and the two main environmental factors of moon phase and current directions. PCA with arrows $(\mathbf{b})$ highlights the direction of the taxa at increasing values of the environmental variables (performed with CANOCO 5).

The hierarchical cluster analysis performed with Primer v7 shows 5 main clusters based on the taxa presence and the current direction as environmental factor (Figure 4). 


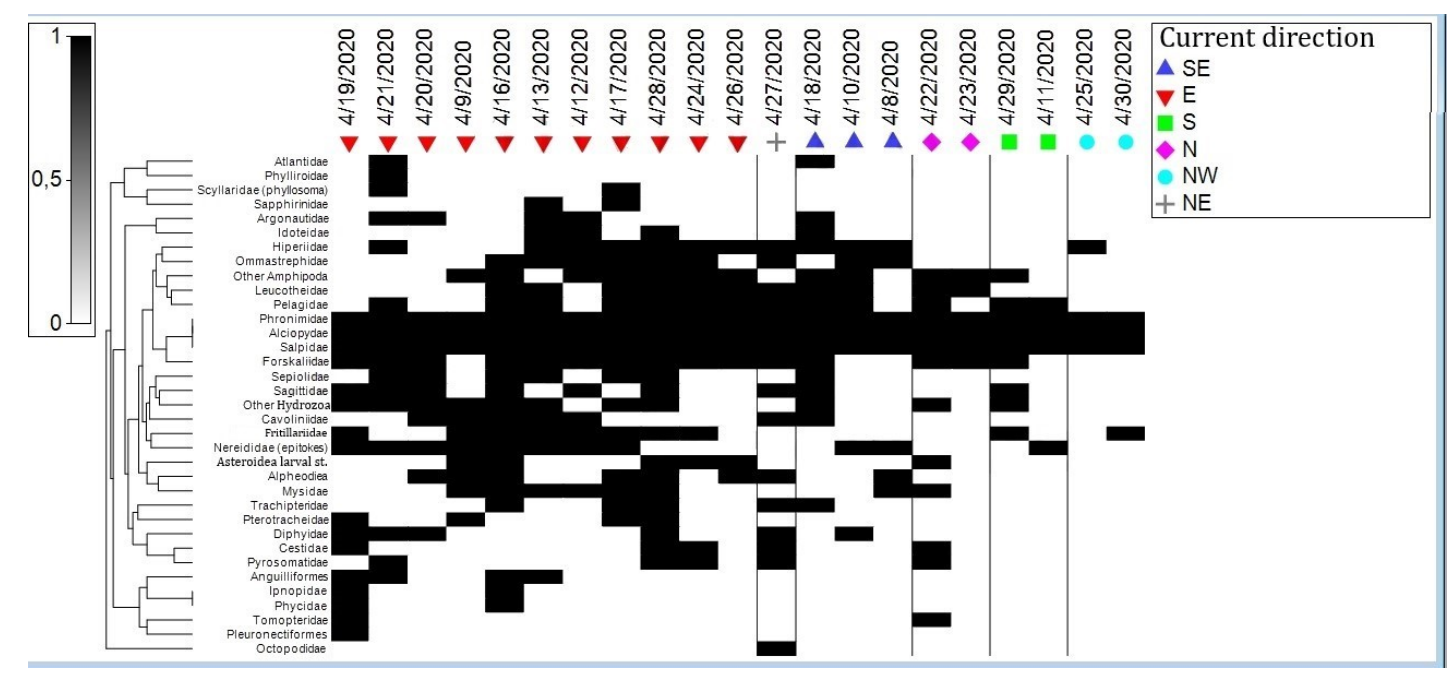

Figure 4. Dendogram plot performed by Primer v7 combined with the shadow plot for the presence (from 0 to 1 ) in the monitored time and the daily current direction.

According to the statistical analyses on the relation between environmental constrains and species diversity, the contribution of the eastern currents in shaping plankton communities is well supported (see Figure 4). Lowest level of plankton diversity is related to north western stream, which can be considered local, as the diving site results covered by the island from this direction ( $0.8 \mathrm{~nm}$ off the bank). Species diversity mainly reflects typical pelagic assemblages, whereas the occurrence of emergent zooplankton (Amphipoda, Nereidae) and more benthic species (Octopodidae) can be considered mainly influenced by the contribution of the nearby shallow water banks ("Secca delle Formiche") and affected by moon phase rather than current direction. The occurrence of other larval and juvenile stages, as for Anguilliformes, Phycidae, Pleuronectiformes, and Scyllaridae (Figure 4), showed a clear convergence in the contribution of current direction (Figure 4) and moon phase (Supplementary Materials, Figure S3), which may be related to a shared behavioural form of detection avoidance.

\subsection{Behavioral Traits of T. trachypterus}

Over the whole study period, a total of 18 juveniles of T. trachypterus were observed, photographed and filmed during SCUBA dives at night between the 16th and the 28th of April 2018. Prolonged observations ( $>2 \mathrm{~min}$ ) of the specimens were possible only for 10 fish, given the high avoidance behaviour of the species. Juveniles were observed swimming between 0.5 and $7 \mathrm{~m}$ below the surface, with the body obliquely or almost vertically pointed with the head towards the surface. Locomotion was performed through undulating movements of the long dorsal fin only, except for the anterior prolonged dorsal fin rays that showed limited oscillating movements (Supplementary Materials, Video 1-10). A faster escaping movement was displayed using the whole body, as showed in Supplementary Materials, Video 8. Pelvics and caudal fin remained spread, but substantially motionless or with small and occasional "snap" movements. While dorsal and pectoral fin membranes were entirely translucent, those of the wide pelvic and caudal fins showed orange blotches, with rays protruding far over the fin membrane. In some cases, juveniles oriented the dorsal or abdominal surface towards the observer, greatly limiting the area exposed to the view of the observer itself (Figure 5C,D; Supplementary Materials, Video 5-7, 9-10). At the same time, caudal and pelvic fins were maintained orthogonal to the observer, with a significant torsion of the caudal fin up to $90^{\circ}$ angle (Figure 5C). This latter behaviour was displayed for a prolonged time. 


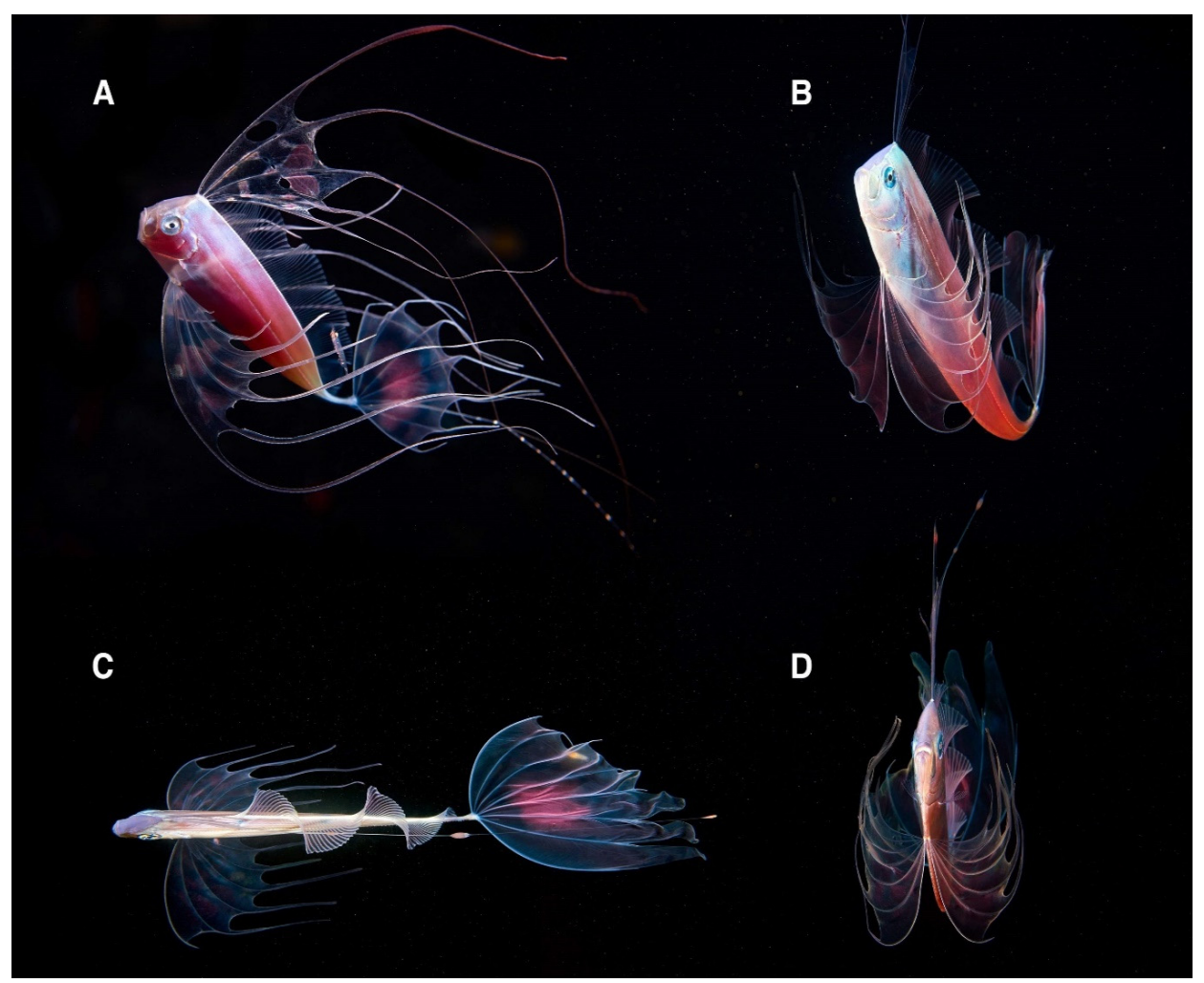

Figure 5. Lateral (A), fronto-lateral (B), dorsal (C), and frontal (D) view of juvenile specimens of T. trachypterus, with detail of fins orientation accordingly to the observer visual axis.

Fish were also observed rapidly protruding their jaws, probably preying on small planktonic organisms (Supplementary Materials, Video 4), that were very abundant in the surface water column in which specimens were observed.

Four specimens were caught by hand net and preserved in alcohol for laboratory analysis. All the main morphometric parameters are reported in Supplementary Materials, Table S2.

\section{Discussion}

\subsection{Ponza Island Coastal front and Pelagic Biodiversity}

Biological-physical interactions structure the variability of the marine environment at a wide range of spatial and temporal scales, affecting population dynamics and trophic interactions $[42,43]$. Such example is a front, a physical interface with gradients of water properties that include temperature, salinity, and turbidity [44,45]. Fronts occur across the world oceans, ranging from basin-scale features to small river plumes, and can be persistent or ephemeral $[44,46]$. Frontal zones are often associated with enhanced biomass, and may serve as an important foraging grounds by aggregating species from multiple trophic levels [47-49], being key habitats for successful energy transfer through food webs. In situ observations and modelling studies suggest that mesoscale and sub-mesoscale processes may affect biodiversity in the Mediterranean Sea, especially where coastal morphology and intense wind stress lead to the formation of energetic filaments [50,51], contributing to the dispersal of coastal inputs towards the open sea, along with plankton.

Ponza Island is located in the western sector of the Pontine volcanic archipelago and originated during the Plio-Pleistocene on the outer margin of the Latium continental shelf. The island slope rapidly sinks to deep waters bottoms, especially on the east and south-west side (Figure 1). Winds are known to support the organic enrichment process of offshore waters, bringing the contribution of coastal freshwater input. Available time lapse records of Ponza Island and Gaeta showed three prevalent wind directions, the eastern one of which can be considered the most relevant, both in terms 
of intensity and frequency. This is clearly shown by the SS map presented in Supplementary Materials, Figures S1C and S2. The overlap of deep water pools, eutrophic waters, and wind driven currents may lead to an organic enrichment in the study site, due to both the upwelling and the contribution of coastal freshwater waters, supporting an increase in plankton biodiversity. Vertical transport has a well known effect in increasing the biodiversity of the photic layers only in restricted areas, as, for example, where convection is sufficiently deep, in a small number of frontal regions and in the few upwelling sites. Coastal inputs have thus an important role in sustaining food webs in the whole Mediterranean Sea [52].

Despite the data acquired in this expedition they cannot be considered exhaustive to completely depict these processes (both in terms of temporal and sampling extension), they show intriguing insights into the relation between local hydrodynamism and plankton diversity. This latter conclusion is enhanced by the record of a number of rare species, some of which appear to be far less rare than thought. An example is the case of the larval stages of the tripod fish Bathypterois sp., for which, to the best of our knowledge, we provide the first available photo in environment; see Supplementary Materials, Plate IV). Despite the short period of the investigation conducted in this work, over the annual cycle, mesozooplankton abundance in offshore waters of the Tyrrhenian Sea oscillated within a narrow range and revealed lower seasonal variability [53,54], with peaks occurring in April.

Moonlight has been documented to affect the distribution of plankton biodiversity, with cyclic patterns of vertical movement synchronised with variations of irradiance in all aquatic habitats [55]. Species abundances are higher during new moon and lower during full moon, suggesting that predation pressure from planktivorous species may affect plankton abundance [55]. Moon phase is also used by species to synchronize reproduction [55].

Occurrence of species during the studied period showed two different scenarios according to the moon phase. Whereas the abundance of most taxa [23] seemed not to be directly correlated only with moon cycle, for 12 taxa, there was a clear correlation between their occurrence and moon phases (Supplementary Materials, Figure S3). With the exception of Cestidae, all the other groups of moon-affected taxa clearly avoided full moon. Interestingly, field observation of some of them revealed mating behaviour, such as for Nereids (Supplementary Materials, Plate I), Sepiolidae, and Idioteidae (Supplementary Materials, Plate II), and trophic interactions (Supplementary Materials, Plate III). Juvenile and larval stages of fish were also abundant during the night with a weak moon light, as a direct consequence of lower predation rate [55] (see Supplementary Materials, Plate IV).

\subsection{Ecological Insight on the Uncommon Mesopelagic Fish Trachipterus trachypterus}

Trachipterus trachypterus is considered rare and with low population densities; however, the mesopelagic habits of the species could lead to an underestimation of its abundance [28]. This fish is only occasionally caught with professional fishing gear, and usually as one or two specimens. Most of the specimens are caught by longline or trawl at depth of 370-700 $\mathrm{m}[21,24,28,56]$; in other cases, they were caught by hand, or observed near the surface or stranded $[20,28]$. In the present study, the species was observed and caught in exceptionally large numbers. The presence of several juveniles of $T$. trachypterus in the study area could be related to the favorable hydrological and ecological conditions typical of banks and nearby areas. Banks are important areas for fish biodiversity and often host poorly known and rare fish species [57]. Uncommon species, such as T. trachypterus, could be good indicators of environmental changes; however, data about the ecology and biology of this species remain scarce.

In ecological communities, it is generally believed that the principal survival option available to marine fish larvae is a fast growth and a quick enhancement of swimming performances [58-60]. The occurrence of T. trachypterus displayed a circa-lunar cycle, in contrast with what observed with juveniles of other fish species. A more in depth analysis showed that specimens collected referred to two different size ranges, with the bigger ones $(229-157 \mathrm{~mm}$ ) sampled during almost full moon nights (Supplementary Materials, Table S2, specimens 1 and 2) and the smallerones (91-58 mm) during 
darkest nights (see also Supplementary Materials, Table S1). Despite the fact that this correlation must be supported by further observations, it is reasonable that the species behaviour changes according to the size, and that it occurs in the surface layer of the pelagic domain as a consequence of hiding or planktotrophic behaviour.

The larval fish phenotype also may have a strong impact on predation through dissembling or active defenses against predators. Diverse and complex morphologies can be found within the same family [61,62], suggesting the occurrence of different predation strategies, even if visual predation by larger fishes is likely the dominant selective force.

Batesian mimicry is a more widespread survival strategy than previously thought, especially within marine communities [63], as demonstrated by the convergence of numbers of distantly related fish taxa on the production of complex features (especially in larval stages and juveniles), like extremely long fin rays (Gadiformes, Lampridae, Lophiidae, Pleuronectiformes, and Serranidae), external guts (Gadiformes, Myctophidae), and even false eyes on stalks (Myctophidae, Stomiidae) $[62,63]$. Within marine pelagic environments, the evolution of visual Batesian mimicry in larval fishes must meet three fundamental conditions: (1) visual predation must be a strong source of mortality; (2) there must be a relatively common and functional model that the mimic resembles through morphology or behavior, and (3) mimics with only a slight resemblance to the model receives some degree of protection [64,65].

Within this expedition, we had the chance to observe, for the first time, some peculiar behavioural traits of juveniles of T. trachypterus which may be linked to Batesian mimicry.

The almost vertical position taken by juveniles of T. trachypterus during swimming and the dorsal-fin based locomotion recorded during our study is in agreement with the swimming behaviour previously reported for juveniles of the same species [66]. A similar swimming behaviour was recently reported also for juveniles of T. arcticus [67]. On the other hand, new data emerge from our study: 1- the "dorsal/ventral surface exhibition", in which the juvenile fish oriented its dorsal/ventral surface towards the observer; 2 - the potential Batesian mimicry. We hypothesise that these two behaviours are related. Dorsal-orienting swimming behaviour may represent a strategy to hide the general shape of the fish and, at the same time, the extension and orientation of caudal and pelvic fins to the potential predator may enhance its appearance as a noxious (or not palatable) organism. The small occasional snap movements of these fins further recall a jellyfish species as a model for the Batesian mimicry (e.g., Pelagia noctiluca). Noteworthy, the elongated rays of the anterior part of the dorsal fin and the small orange expansions on these rays are similar in appearance to the cormidia of siphonophores. These peculiar morphological traits seem not to be conserved in the adult and therefore can be considered a functional adaptation to reduce predation risks during the juvenile epipelagic stage of the species. Indeed, this has already been suggested for juveniles and larvae of other mesopelagic fish species, in which particularly long and delicate fins (often in association with specific behaviours and colors) play an important role in reducing mortality due to predation $[63,68-70]$.

\section{Conclusions}

Despite the numerous investigations of the last decades, the emerging picture of plankton dynamics in the Mediterranean Sea is still largely unexplored. Many factors, such as the structure of the seafloor and continental water inflows, may represent core drivers in the distribution of plankton diversity, structuring complex and dynamic trophic interactions between coastal and pelagic environments. In this research, we show how the vertical transport of coastal nutrients close to the continental shelf boundary sustains a high planktonic diversity and the occurrence of rare mesopelagic fish species. Furthermore, for a total of 12 taxa, a clear correlation between their presence and moon phases is reported.

The concept behind AQUATILIS field-based approach, along with the use of modern filming equipment, allowed us to describe, for the first time, the behaviour of the uncommon mesopelagic fish T. trachypterus, depicting the presence of Batesian mimicry in juveniles, and to observe and photograph 
rare and little known species, such as the larva of Bathypterois sp. Our results support the role of field studies as a fundamental instrument improving our knowledge on complex ecosystems, as those inhabited by the mesopelagic communities.

Supplementary Materials: The following are available online at http://www.mdpi.com/2077-1312/8/8/581/s1: Table S1-Planktonic taxa surveyed at the diving site; Figure S1-(a) and (b) show respectively the wind rose of Ponza (2011-2015) and Gaeta (2007-present). Map (c) and (d) show respectively the mean distribution of SST and Salinity from 1987 to present; Figure S2-In the panel (a) is presented in descending order the distribution of SST during 9th-11th of April, during 12th-18th of April and during 19th-28th of April. In the panel (b) the polar scatter of wind indicates the direction (polar orientation) and intensity of wind (x-axis). In the panel (c) is presented in descending order the distribution of Salinity during 9th-11th of April, during 12th-18th of April and during 19th-28th of April; Figure S3-Taxa occurrence according to moon phase; Figure S4. The four sampled juvenile specimens of Trachipterus trachypterus from the central Tyrrhenian Sea (A-C), measurements are reported in Table S2; Table S2. Morphometric measurements of the four juvenile specimens of T. trachypterus reported in Figure S4 and collected in the central Tyrrhenian Sea; Plate I. Mating behaviour observed during the surveyed period (A) nereids epitokes mating close to the surface; (B) details of epitokes releasing eggs; Plate II. Mating behaviour observed during the surveyed period: (A) Idioteidae on a feather; (B) Sepiolidae; Plate III. Trophic interaction within plankton community, observed during the surveyed period: (A) Scyllaridae phyllosoma feeding on a salp, with detail of its peculiar interaction with jellyfish species as a floating support; (B) Phylliroe cfr. lichtensteinii feeding on a jellyfish; (C) Pelagia noctiluca feeding on a salp; Plate IV. Fish juvenile/larval stages recorded during the expedition: (A) Phycidae (Phycis cf. phycis); (B) Ipnopidae (Bathypterois sp.); (C) Pleuronectiformes; (D) Anguilliformes. Video 1-10. Tracks of behavioural traits of interest. Available online at https://doi.org/10.5281/zenodo.3934365.

Author Contributions: Conceptualization, A.M., A.S., E.B. and F.T.; Methodology, A.M., A.S. and F.T.; Formal Analysis, A.M., F.P.d.M., A.D. and F.T.; Investigation, A.M., A.S. and E.B.; Resources, A.M. and A.S.; Data Curation, A.M., F.P.d.M. and A.D.; Writing-Original Draft Preparation, A.M., F.P.d.M., A.D. and F.T.; Writing-Review \& Editing, A.M., A.S., F.P.d.M., A.D., E.B. and F.T.; Project Administration, A.M. and A.S.; Funding Acquisition, A.M. All authors have read and agreed to the published version of the manuscript.

Funding: This research received no external funding.

Acknowledgments: We are keen to thank the AQUATILIS teams and crew, with a special mention for Fedor Bolshakov, Dmitry Ozerov, and Pavel Kremenets. A special thanks to Sviatlana Semenova, for supporting and supervising all the field activities during the expedition. We gratefully acknowledge the AQUATILIS Association for funding the expedition and for the logistic supplies.

Conflicts of Interest: The authors declare no conflict of interest.

\section{References}

1. Lévy, M.; Jahn, O.; Dutkiewicz, S.; Follows, M.J.; D'Ovidio, F. The dynamical landscape of marine phytoplankton diversity. J. R. Soc. Interface 2015, 12, 20150481. [CrossRef]

2. Ferrari, R.; Wunsch, C. Ocean Circulation Kinetic Energy: Reservoirs, Sources, and Sinks. Annu. Rev. Fluid Mech. 2009, 41, 253-282. [CrossRef]

3. McGillicuddy, D.J. Mechanisms of Physical-Biological-Biogeochemical Interaction at the Oceanic Mesoscale. Ann. Rev. Mar. Sci. 2016, 8, 125-159. [CrossRef]

4. Mahadevan, A.; Campbell, J.W. Biogeochemical patchiness at the sea surface. Geophys. Res. Lett. 2002, 29, 31-32. [CrossRef]

5. Lehahn, Y.; D'Ovidio, F.; Koren, I. A Satellite-Based Lagrangian View on Phytoplankton Dynamics. Ann. Rev. Mar. Sci. 2018, 10, 99-119. [CrossRef] [PubMed]

6. McManus, M.A.; Woodson, C.B. Plankton distribution and ocean dispersal. J. Exp. Biol. 2012, 215, $1008-1016$. [CrossRef] [PubMed]

7. McDonald, L.L. Sampling rare populations. In Sampling Rare or Elusive Species; Thompson, W., Ed.; Island Press: Washington, DC, USA, 2004; pp. 11-42.

8. Kelly, R.P.; Port, J.A.; Yamahara, K.M.; Martone, R.G.; Lowell, N.; Thomsen, P.F.; Mach, M.E.; Bennett, M.; Prahler, E.; Caldwell, M.R.; et al. Harnessing DNA to improve environmental management. Science 2014, 344, 1455-1456. [CrossRef] [PubMed]

9. Wuertz, M. Mediterranean Pelagic Habitat: Oceanographic and Biological Processes, an Overview; IUCN: Gland, Switzerland, 2010; ISBN 978-2-8317-1242-0. 
10. Bonanno, A.; Zgozi, S.; Basilone, G.; Hamza, M.; Barra, M.; Genovese, S.; Rumolo, P.; Nfate, A.; Elsger, M.; Goncharov, S.; et al. Acoustically detected pelagic fish community in relation to environmental conditions observed in the Central Mediterranean sea: A comparison of Libyan and Sicilian-Maltese coastal areas. Hydrobiologia 2015, 755, 209-224. [CrossRef]

11. Giannoulaki, M.; Iglesias, M.; Tugores, M.P.; Bonanno, A.; Patti, B.; De Felice, A.; Leonori, I.; Bigot, J.L.; Tičina, V.; Pyrounaki, M.M.; et al. Characterizing the potential habitat of European anchovy Engraulis encrasicolus in the Mediterranean Sea, at different life stages. Fish. Oceanogr. 2013, 22, 69-89. [CrossRef]

12. Tugores, P.; Giannoulaki, M.; Iglesias, M.; Bonanno, A.; Tičina, V.; Leonori, I.; MacHias, A.; Tsagarakis, K.; Díaz, N.; Giráldez, A.; et al. Habitat suitability modelling for sardine Sardina pilchardus in a highly diverse ecosystem: The Mediterranean Sea. Mar. Ecol. Prog. Ser. 2011, 443, 181-205. [CrossRef]

13. Damgaard, C.; Weiner, J. It's About Time: A Critique of Macroecological Inferences Concerning Plant Competition. Trends Ecol. Evol. 2017, 32, 86-87. [CrossRef] [PubMed]

14. Watson, D.L.; Harvey, E.S.; Fitzpatrick, B.M.; Langlois, T.J.; Shedrawi, G. Assessing reef fish assemblage structure: How do different stereo-video techniques compare? Mar. Biol. 2010, 157, 1237-1250. [CrossRef]

15. Olney, J.E.; McBride, R.S. Intraspecific variation in batch fecundity of American shad: Revisiting the paradigm of reciprocal latitudinal trends in reproductive traits. Am. Fish. Soc. Symp. 2003, 2003, 185-192.

16. Walters, V.; Fitch, J. The families and genera of the lampridiform (Allotriognath) suborder Trachipteroidei. Calif. Fish Game 1960, 46, 441-451.

17. Froese, R.; Pauly, D. FishBase. Available online: www.fishbase.org (accessed on 1 May 2018).

18. Dulčić, J. First record of ribbon fish larva, Trachipterus trachypterus, from the Eastern Adriatic. Cybium 1996, 20, 101-102.

19. Dulčić, J. First record of scalloped ribbon fish, Zu cristatus (Pisces: Trachipteridae), eggs in the Adriatic Sea. J. Plankton Res. 2002, 24, 1245-1246. [CrossRef]

20. Borme, D.; Voltolina, F. On the occurrence of ribbon fish Trachipterus trachypterus (Gmelin, 1789) in the Gulf of Trieste (northern Adriatic Sea). Ann. Ser. Historia Nat. 2006, 16, 181.

21. Psomadakis, P.N.; Scacco, U.; Vacchi, M. Recent findings of some uncommon fishes from the central Tyrrhenian Sea. Cybium 2006, 30, 297-304.

22. Psomadakis, P.N.; Bottaro, M.; Vacchi, M. On two large specimens of Zu cristatus (Trachipteridae) from the Gulf of Genoa (NW Mediterranean). Cybium 2007, 31, 480-482.

23. Bradai, M.N.; El Ouaer, A. New record of the scalloped ribbon fish, Zu cristatus (Osteichthyes: Trachipteridae) in Tunisian waters (central Mediterranean). Mar. Biodivers. Rec. 2014, 5, e59. [CrossRef]

24. Mytilineou, C.; Anastasopoulou, A.; Christides, G.; Bekas, P.; Smith, C.J.; Papadopoulou, K.N.; Lefkaditou, E.; Kavadas, S. New records of rare deep-water fish species in the Eastern Ionian Sea (Mediterranean Sea). J. Nat. Hist. 2013, 47, 1645-1662. [CrossRef]

25. Bono, G.; Gancitano, S.; Bosch-Belmar, M.; Giusto, G.B.; Okpala, C.O.R.; Scannella, D.; Geraci, M.L.; Falsone, F. Occurrence of two rare species from order Lampriformes: Crestfish Lophotus lacepede (Giorna, 1809) and scalloped ribbonfish $\mathrm{Zu}$ cristatus(Bonelli, 1819) in the northern coast of Sicily, ItalyPojava dviju rijetkih vrsta iz reda Lampriformes: B. Acta Adriat. 2017, 58, 137-146. [CrossRef]

26. Bianco, P.G.; Zupo, V.; Ketmaier, V. Occurrence of the scalloped ribbonfish Zu cristatus (Lampridiformes) in coastal waters of the central Tyrrhenian Sea, Italy. J. Fish Biol. 2006, 68, 150-155. [CrossRef]

27. Crocetta, F.; Agius, D.; Balistreri, P.; Bariche, M.; Bayhan, Y.K.; Çakir, M.; Ciriaco, S.; Corsini-Foka, M.; Deidun, A.; El Zrelli, R.; et al. New mediterranean biodiversity records (October 2015). Mediterr. Mar. Sci. 2015, 16, 682-702. [CrossRef]

28. Tiralongo, F.; Lillo, A.O.; Tibullo, D.; Tondo, E.; Martire, C.L.; D’Agnese, R.; Macali, A.; Mancini, E.; Giovos, I.; Coco, S.; et al. Monitoring uncommon and non-indigenous fishes in Italian waters: One year of results for the AlienFish project. Reg. Stud. Mar. Sci. 2019, 28, 100606. [CrossRef]

29. Paladini de Mendoza, F.; Bonamano, S.; Martellucci, R.; Melchiorri, C.; Consalvi, N.; Piermattei, V.; Marcelli, M. Circulation during storms and dynamics of suspended matter in a sheltered coastal area. Remote Sens. 2018, 10, 602. [CrossRef]

30. Martellucci, R.; Pierattini, A.; Paladini de Mendoza, F.; Melchiorri, C.; Piermattei, V.; Marcelli, M. Physical and biological water column observations during summer sea/land breeze winds in the coastal northern Tyrrhenian Sea. Water (Switzerland) 2018, 10, 1673. [CrossRef] 
31. Kronfeld-Schor, N.; Dominoni, D.; de la Iglesia, H.; Levy, O.; Herzog, E.D.; Dayan, T.; Helfrich-Forster, C. Chronobiology by moonlight. Proc. R. Soc. B Biol. Sci. 2013, 280, 20123088. [CrossRef]

32. Last, K.S.; Hobbs, L.; Berge, J.; Brierley, A.S.; Cottier, F. Moonlight Drives Ocean-Scale Mass Vertical Migration of Zooplankton during the Arctic Winter. Curr. Biol. 2016, 26, 244-251. [CrossRef]

33. Benoit-Bird, K.J.; Au, W.W.L.; Wisdom, D.W. Nocturnal light and lunar cycle effects on diel migration of micronekton. Limnol. Oceanogr. 2009, 54, 1789-1800. [CrossRef]

34. Drazen, J.C.; De Forest, L.G.; Domokos, R. Micronekton abundance and biomass in Hawaiian waters as influenced by seamounts, eddies, and the moon. Deep Sea Res. Part I Oceanogr. Res. Pap. 2011, 58, 557-566. [CrossRef]

35. Rubolini, D.; Maggini, I.; Ambrosini, R.; Imperio, S.; Paiva, V.H.; Gaibani, G.; Saino, N.; Cecere, J.G. The Effect of Moonlight on Scopoli's Shearwater Calonectris diomedea Colony Attendance Patterns and Nocturnal Foraging: A Test of the Foraging Efficiency Hypothesis. Ethology 2015, 121, 284-299. [CrossRef]

36. Aksnes, D.L.; Røstad, A.; Kaartvedt, S.; Martinez, U.; Duarte, C.M.; Irigoien, X. Light penetration structures the deep acoustic scattering layers in the global ocean. Sci. Adv. 2017, 3, e1602468. [CrossRef] [PubMed]

37. Ochoa, J.; Maske, H.; Sheinbaum, J.; Candela, J. Diel and lunar cycles of vertical migration extending to below $1000 \mathrm{~m}$ in the ocean and the vertical connectivity of depth-tiered populations. Limnol. Oceanogr. 2013, 58, 1207-1214. [CrossRef]

38. Anderson, M.J. Permutation tests for univariate or multivariate analysis of variance and regression. Can. J. Fish. Aquat. Sci. 2001, 58, 626-639. [CrossRef]

39. Anderson, M.J.; Gorley, R.N.; Clarke, K.R. PERMANOVA+ for PRIMER: Guide to Software and Statistical Methods; PRIMER-E: Plymouth, UK, 2008; pp. 1-214.

40. Villegas-Zurita, F.; Castillejos-Moguel, F.; Benítez-Villalobos, F.; Urbán-Ramírez, J. Alpha diversity of marine mammals of the Mexican South Pacific. Rev. Mex. Biodivers. 2018, 89, 898-909. [CrossRef]

41. Morris, C. Multivariate Analysis of Ecological Data Using Canoco 5. Afr. J. Range Forage Sci. 2015, 32, $289-290$. [CrossRef]

42. Bakun, A.; Agostini, V.N. Seasonal patterns of wind-induced upwelling/downwelling in the Mediterranean Sea. Sci. Mar. 2001, 65, 243-257. [CrossRef]

43. Haury, L.R.; McGowan, J.A.; Wiebe, P.H. Patterns and Processes in the Time-Space Scales of Plankton Distributions. In Spatial Pattern in Plankton Communities; Springer: New York, NY, USA, 1978; pp. $277-327$.

44. Le Fèvre, J. Aspects of the Biology of Frontal Systems. Adv. Mar. Biol. 1987, 23, 163-299. [CrossRef]

45. Joyce, T.M. Varieties of ocean fronts. In Baroclinic Instability and Ocean Fronts; Technical Report No. 83-41; Woods Hole Oceanographic Institution: Falmouth, MA, USA, 1983; Volume 1, p. 59.

46. Belkin, I.M.; Cornillon, P.C.; Sherman, K. Fronts in Large Marine Ecosystems. Prog. Oceanogr. 2009, 81, $223-236$. [CrossRef]

47. Franks, P.J.S. Phytoplankton blooms at fronts: Patterns, scales, and physical forcing mechanisms. Rev. Aquat. Sci. 1992, 6, 121-137.

48. Genin, A.; Jaffe, J.S.; Reef, R.; Richter, C.; Franks, P.J.S. Swimming against the flow: A mechanism of zooplankton aggregation. Science 2005, 308, 860-862. [CrossRef] [PubMed]

49. Bost, C.A.; Cotté, C.; Bailleul, F.; Cherel, Y.; Charrassin, J.B.; Guinet, C.; Ainley, D.G.; Weimerskirch, H. The importance of oceanographic fronts to marine birds and mammals of the southern oceans. J. Mar. Syst. 2009, 78, 363-376. [CrossRef]

50. Bignami, F.; Böhm, E.; D'Acunzo, E.; D'Archino, R.; Salusti, E. On the dynamics of surface cold filaments in the Mediterranean Sea. J. Mar. Syst. 2008, 74, 429-442. [CrossRef]

51. Wang, D.-P.; Vieira, M.E.C.; Salat, J.; Tintoré, J.; La Violette, P.E. A shelf/slope frontal filament off the northeast Spanish Coast. J. Mar. Res. 2008, 46, 321-332. [CrossRef]

52. Siokou-Frangou, I.; Christaki, U.; Mazzocchi, M.G.; Montresor, M.; Ribera D'Alcala, M.; Vaque, D.; Zingone, A. Plankton in the open mediterranean Sea: A review. Biogeosciences 2010, 7, 1543-1586. [CrossRef]

53. Di Carlo, B.S.; Ianora, A.; Fresi, E.; Hure, J. Vertical zonation patterns for mediterranean copepods from the surface to $3000 \mathrm{~m}$ at a fixed station in the Tyrrhenian Sea. J. Plankton Res. 1984, 6, 1031-1056. [CrossRef]

54. de Puelles, M.L.F.; Pinot, J.-M.; Valencia, J. Variabilite saisonniere et interannuelle du zooplancton au large de Majorque (mer des Baleares, Mediterranee occidentale). Oceanol. Acta 2003, 5, 673-686.

55. Chakraborty, U. Effects of different phases of the lunar month on living organisms. Biol. Rhythm Res. 2020, 51, 254-282. [CrossRef] 
56. Farias, I.; Moura, T.; Figueiredo, I.; Vieira, A.R.; Serra-Pereira, B.; Serrano Gordo, L. Northernmost occurrence of the ribbonfish Trachipterus trachypterus (Gmelin, 1789) in the NE Atlantic: The Portuguese continental shelf: Short communication. J. Appl. Ichthyol. 2010, 26, 143-144. [CrossRef]

57. Consoli, P.; Esposito, V.; Battaglia, P.; Altobelli, C.; Perzia, P.; Romeo, T.; Canese, S.; Andaloro, F. Fish distribution and habitat complexity on banks of the strait of sicily (central mediterranean sea) from Remotely-Operated Vehicle (ROV) explorations. PLoS ONE 2016, 11, e0167809. [CrossRef] [PubMed]

58. Houde, E.D. Fish Early Life Dynamics and Recruitment Variability. In Proceedings of the American Fisheries Society Symposium, 10 Annual Larval Fish Conference, Miami, FL, USA, 18-23 May 1987.

59. Anderson, J.T. A Review of Size Dependant Survival during Pre-recruit Stages of Fishes in Relation to Recruitment. J. Northwest Atl. Fish. Sci. 1988, 8, 55-66. [CrossRef]

60. Hare, J.A.; Cowen, R.K. Size, growth, development, and survival of the planktonic larvae of Pomatomus saltatrix (Pisces: Pomatomidae). Ecology 1997, 78, 2415-2431. [CrossRef]

61. Wells, K.D. The Origin and Evolution of Larval Forms. Copeia 2000. [CrossRef]

62. Miller, B.S.; Kendall, A.W. Early Life History of Marine Fishes; University of California Press: Berkeley, CA, USA, 2009; ISBN 9780520249721.

63. Greer, A.T.; Woodson, C.B.; Guigand, C.M.; Cowen, R.K. Larval fishes utilize Batesian mimicry as a survival strategy in the plankton. Mar. Ecol. Prog. Ser. 2016, 551,1-12. [CrossRef]

64. Huheey, J.E. Mathematical Models of Mimicry. Am. Nat. 1988, 131, S22-S41. [CrossRef]

65. Caley, M.J.; Schluter, D. Predators favour mimicry in a tropical reef fish. Proc. R. Soc. B Biol. Sci. 2003, 270, 667-672. [CrossRef]

66. Nishimura, S.; Hirosaki, Y. Observations on the swimming behavior of some taeniosomous fishes in aquaria and in nature. Publ. Seto Mar. Biol. Lab. 1964, 12, 165-171. [CrossRef]

67. Moritz, T.; Stümer, D.; Jakobsen, K.; Jakobsen, J. Observations on two live specimens of Trachipterus arcticus (Lampriformes: Trachipteridae) from the Azores. Cybium 2015, 39, 78-80.

68. Sazima, I. Juvenile grunt (Haemulidae) mimicking a venomous leatherjacket (Carangidae), with a summary of Batesian mimicry in marine fishes. J. Ichthyol. Aquat. Biol. 2002, 6, 61-68.

69. Reininger, M. Mimicry in juvenile wrasses: Ecological and behavioural aspects of a coris-amphiprion relationship in the northern red sea. Zool. Middle East 2011, 54, 23-34. [CrossRef]

70. Tan, H.H. Apparent mimicry of jellyfish by juvenile pomfret, Pampus chinensis (Teleostei: Stromateidae). Nat. Singap. 2008, 1, 139-142.

(C) 2020 by the authors. Licensee MDPI, Basel, Switzerland. This article is an open access article distributed under the terms and conditions of the Creative Commons Attribution (CC BY) license (http://creativecommons.org/licenses/by/4.0/). 